\title{
Spatial and Temporal Variability of Precipitation in Haihe River Basin, China: Characterization and Management Implications
}

\author{
Yuzhou Luo, ${ }^{1,2}$ Zhonggen Wang, $^{1,3}$ Xiaomang Liu, ${ }^{1}$ and Minghua Zhang ${ }^{2}$ \\ ${ }^{1}$ Key Laboratory of Water Cycle and Related Land Surface Processes, Institute of Geographical Science \\ and Natural Resources Research, Chinese Academy of Science, Beijing 100101, China \\ ${ }^{2}$ Department of Land, Air, and Water Resources, University of California, Davis, CA 95816, USA \\ ${ }^{3}$ State Key Laboratory of Simulation and Regulation of Water Cycle in River Basin, \\ China Institute of Water Resources and Hydropower Research, Beijing 100038, China
}

Correspondence should be addressed to Zhonggen Wang; wangzg@igsnrr.ac.cn

Received 21 May 2014; Accepted 20 June 2014; Published 14 July 2014

Academic Editor: Eduardo García-Ortega

Copyright (C) 2014 Yuzhou Luo et al. This is an open access article distributed under the Creative Commons Attribution License, which permits unrestricted use, distribution, and reproduction in any medium, provided the original work is properly cited.

Data analysis and characterization of precipitation in the Haihe River Basin (HRB) of China are required for management practices for the purpose of flood water control and utilization. In the companion paper, we presented precipitation data in the HRB during 1951-2010 and reported its basic statistics such as temporal trend and spatial variability. In this study, spatiotemporal variability on the precipitation was further investigated comprehensively for the underlying physics and the implication to water resource management. During the summer flood season of the study area, basin-wide precipitation was negatively correlated to average NINO3.4 index. Spatially, summer precipitation was correlated with gridded sea surface temperature (SST) observed in the eastern tropic Pacific Ocean and the western tropic Indian Ocean. SST in two representative areas was identified as potential predictors for precipitation in the HRB. No spatial or temporal correlations were confirmed between precipitation and soil moisture as annual averages in the study area. Copula analysis suggested about $40 \%$ possibility in a year with a potential for cross-watershed water diversion within HRB.

\section{Introduction}

Precipitation is considered as one of the most important variables for characterizing water resources and understanding the climatic impacts on local hydrologic system, especially for the areas facing severe water crisis such as the Haihe River Basin (HRB) of China. Sustainable socioeconomic development of the HRB was threatened by serious water shortage, relating to the rapid growth in population and economy, limited water resources and their uneven distribution in both time and space, and low water use efficiency. Enclosing Beijing and other metropolitan areas, the HRB is the political, economic, and cultural center of China. Annual per capita water resources are only $300 \mathrm{~m}^{3}$, significantly lower than that at national and global averages $[1,2]$. In addition, precipitation decline was reported in our previous study, suggesting a $20 \%$ decrease of precipitation between two periods of 1951-1979 and 1980-2008 [3]. Between the same periods, consequently, surface runoff in this area remarkably decreased by about $40 \%$ [4]. Located in the monsoon region of the East Asia warm temperate zone, precipitation in the HRB is concentrated in a very short period, causing serious floods during rainy seasons. Hydrologic morphology of the HRB has been heavily modified for flood control and water supply. More than 1,900 reservoirs were built in the basin, with total storage capacity of 31.4 billion $\mathrm{m}^{3}$, similar to the total natural runoff amount of 31.6 billion $\mathrm{m}^{3}$ [1]. About $97 \%$ of the capacity is contributed by reservoirs in the mountain areas [5]. Due to the lack of comprehensive analysis on the variations of precipitation on time and space, systematical 
management of the reservoirs is not available, resulting in inefficient utilization of water resources in the basin.

Favorable conditions to the sustainable development in the HRB are predicted for the near future, but they are associated with great uncertainties. It is projected that precipitation in the HRB will increase during the 21st century according to the projection of Intergovernmental Panel on Climate Change (IPCC) climate models [6-9]. This is in contrast to the observed decreasing trend for the past 60 years. In addition, latest measurements in the 21st century did not show a significant increase trend for precipitation. Therefore, the actual effects of climate change on the hydrologic cycle and water resources are associated with great uncertainty. To secure sustainable development and minimize groundwater exploitation, the "South-to-North Water Transfer Project" (SNWTP) of China is under construction with proposed water diversity capability of 13 billion $\mathrm{m}^{3}$ annually from the Danjiangkou Reservoir on the Hanjiang River, a tributary of the Yangtze River to the North China Plain (including 9.0 billion $\mathrm{m}^{3}$ to the HRB, comparable to the total amount of current industrial and domestic uses in the basin). The central route will be ready to divert water starting from the year 2014 and reach its full capacity by 2030 [10]. However, the construction and operation of the SNWTP are associated with great uncertainty. For example, our previous study indicated that the water supply area (the Danjiangkou Reservoir) for the central route might not have sufficient water for diversion in the near future [11]. In addition, an increasing probability of simultaneous dry years between the water source and destination areas was detected, indicating that there would be more of years when the Danjiangkou Reservoir could not meet the demand of water diversion [12].

Atmospheric circulation at global scales has significant effects on regional climate. Because of the large heat capacity and thermal inertia of oceans, the variability of sea surface temperature (SST, usually in the form of anomalies) has been widely used as predictors for regional precipitation over land at various time scales of seasonal to interannual variations. For example, associations between precipitation over the continental United States and SST in the tropical and North Pacific and in the Atlantic were reported in numerous studies [13-18]. Precipitation in the southern China was mainly related to tropical Indo-Pacific SST [19-21], while less studies have been published for the precipitation-SST correlations in North China. Characterization of the spatiotemporal variability on precipitation and its associations with local and global stressors are required for effective water management including the control and utilization of flood water. In addition to remote forcing, local land surface conditions also affect the spatial and temporal variations of seasonal precipitation. Results of previous studies demonstrated potential positive feedback between soil moisture and precipitation [22-24]. For example, antecedent soil moisture could be a predictor for seasonal precipitation in the Upper Mississippi River Basin and the Great Plains of the USA especially during years of large precipitation anomalies [13]. The relationships between soil moisture and precipitation in North China are not reported previously.
Given the limited water resources and great uncertainties on climate change and water diversion, efficient water management with flood control and floodwater utilization would play important roles in the sustainable development of the region. Based on the general analysis on precipitation trend and distributions in our previous study [3], this study aims to further investigate regional and global climate variables as potential predictors for precipitation and evaluate the possibility for cross-watershed water diversion within the basin. The specific study objectives are as follows: (1) to identify the statistical relationships between SST and seasonal precipitation in the $\mathrm{HRB}$, (2) to analyze the correlation between precipitation and antecedent soil moisture in the $\mathrm{HRB}$, and (3) to estimate the joint probability of wet/dry years encountered by different subregions of the basin.

\section{Materials and Methods}

2.1. Site Description. The Haihe River is the largest water system in North China, located between $35-43^{\circ} \mathrm{N}$ latitude and $112-120^{\circ} \mathrm{E}$ longitude (Figure 1). The total drainage area is about $318,200 \mathrm{~km}^{2}$, and majority of the basin is within the Province of Hebei. A very complex hydrology system is observed in the basin. There are nine main rivers and more than 300 tributaries. All rivers are originated from the Taihangshan Mountains to the west or from the Yanshan Mountains of the Mongolian Plateau to the north. Streams generally flow from west to east and discharge into the Bohai Sea. The mountain and plateau region, conventionally defined as areas with elevation higher than $50 \mathrm{~m}$, accounts for $60 \%$ of the total area. Mountain areas, with more than 1,000 reservoirs which contribute $97 \%$ of the total reservoir capacity of the basin, are important for both flood control and water supply in the study area. In the basin floor, stream runoff is highly controlled by dams and reservoirs to satisfy water demands by agricultural and industrial production.

The study area belongs to the semihumid climate in the monsoon region of the East Asia warm temperate zone $[2,25]$, characterized by hot and wet summers and cold and dry winters. Average temperatures in the basin are between -4.9 and $15.0^{\circ} \mathrm{C}$. The average annual precipitation was $535.7 \mathrm{~mm}$ with a coefficient of variation of 0.18 during 1957-2008 [3]. Annual precipitation was mainly contributed by summer months. According to the long-term monthly average precipitation, calendar months are further grouped as the flood season of June to August and the winter dry season of December to February. The flood season includes three months with highest precipitation over a year, accounting for $67 \%$ of annual precipitation. The winter consists of three most dry months contributing only $3 \%$ to the annual precipitation.

\subsection{Data Acquisition}

2.2.1. Precipitation. The monitoring network used in this study included 43 evenly distributed weather stations in the study area (Figure 1). Daily precipitation data during 19512010 was retrieved from China Meteorological Data Sharing 


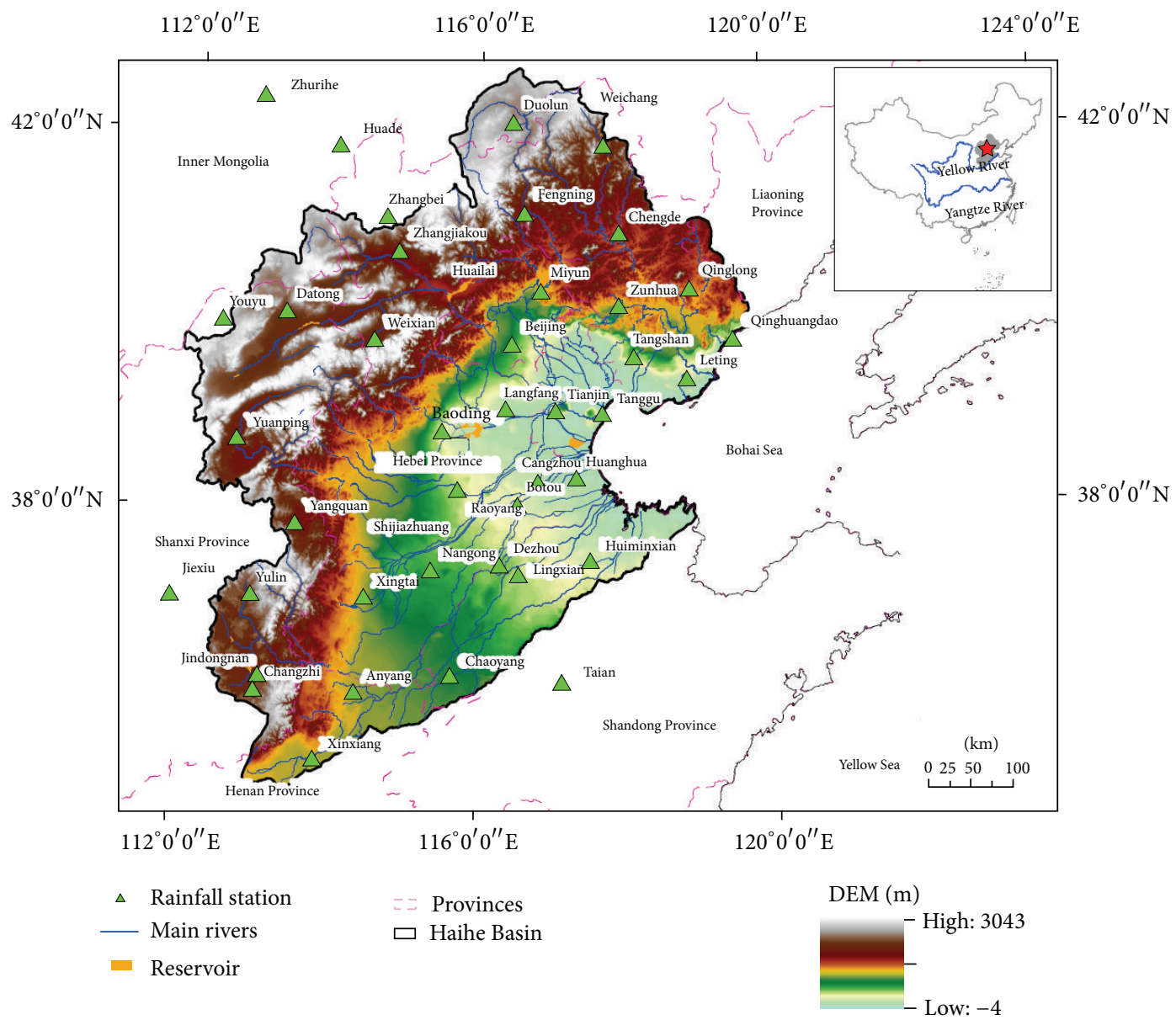

FIgURE 1: The Haihe River Basin and the precipitation monitoring network.

Service System [26]. Monthly and annual averages of precipitation were then calculated from the daily measurements and used in the data analysis of this study. For monthly data, there are about $16 \%$ data missing, mainly for the first three years of 1951-1953. The weather stations without valid data will not be used when calculating basin-wide averages during the months of data missing. More information on the data and network has been provided in the previous study [3].

2.2.2. Sea Surface Temperature. The SST data used in this study are retrieved from the Met Office Hadley Centre Sea Ice and Sea Surface Temperature (http://www .metoffice.gov.uk/hadobs/hadisst/) [27]. Downloaded data includes a monthly global data set spanning the period of 1951-2010, with a $1^{\circ} \times 1^{\circ}$ spatial resolution [27]. The data set was constructed based on in situ sea surface observations and satellite advanced very high resolution radiometer (AVHRR) data.

The Haihe River Basin is dominated by the continental temperate monsoon climate. The variability and predictability of the Asian summer monsoon onset are associated with specific atmospheric circulation characteristics [28]. The atmospheric circulation parameter of Niño3.4 index
(NINO3.4) was selected in this study to investigate the temporal trend of annual rainfall observed in the study area. NINO3.4 is one of El Niño-Southern Oscillation (ENSO) indicators based on sea surface temperatures (SST). It is defined as the average SST anomaly in the region bounded by $5^{\circ} \mathrm{N}$ to $5^{\circ} \mathrm{S}$, from $170^{\circ} \mathrm{W}$ to $120^{\circ} \mathrm{W}$ [27]. Spatial average of SST in this region was calculated and summarized as monthly NINO3.4. An El Niño or La Niña event is identified if the 5 -month running average of the NINO3.4 exceeds $+0.4^{\circ} \mathrm{C}$ for $\mathrm{El}$ Niño or $-0.4^{\circ} \mathrm{C}$ for La Niña for at least 6 consecutive months [29]. The 5-month running average (data is averaged over 5-month, overlapping periods incrementing one month at a time) is used to smooth out variations in sea surface temperature not associated with ENSO.

2.2.3. Soil Moisture. Daily soil moisture data is obtained from the global essential climate variable (ECV) soil moisture data set [30] with spatial resolution of $0.25^{\circ} \times 0.25^{\circ}$, available for the period between $11 / 1 / 1978$ and $12 / 31 / 2010$. The data set was generated based on observations from the C-band scatterometers on board of ERS-1, ERS-2, and METOP-A. Data was downloaded for the study area and calculated as monthly average during 1979-2010 for each grid node. 
The observed ECV soil moisture was compared with the model-calculated NOAA Climate Prediction Center (CPC) soil moisture (version 2). The CPC data covers monthly average soil moisture from 1948 to 2011 with spatial resolution of $0.5^{\circ} \times 0.5^{\circ}[31,32]$. A one-layer "bucket" water balance model was applied in generating the CPC soil moisture, driven by observed monthly precipitation and temperature. In the HRB, preliminary data analysis showed that modeled soil moisture data had significant association with precipitation (annual average: $r=0.608, P<0.001$; monthly data: $r=-0.214, P<0.001)$. However, modeled data showed higher soil moisture from September to November and did not match the observed seasonal variation on soil moisture with wetter conditions in summer months of July-September.

2.3. Data Processing and Analysis. Spatial and temporal variations of precipitation in the HRB have been characterized in our previous study [3]. This study was mainly based on spatial averages of precipitation data during a 60-year period of 19512010 for their implications for water resources management. In addition to the basin-wide average, precipitation was also summarized over subregions of the study area. According to our previous study $[3,33]$, the HRB could be divided into mountain area and basin floor by the elevation of $50 \mathrm{~m}$ and into north and south regions by the latitude $39^{\circ} \mathrm{N}$.

Two approaches to analyzing the SST-precipitation correlation are examined. Monthly NINO3.4 was calculated for 1951-2010 and investigated with the monthly/annual precipitation in the HRB. Based on a sequential Mann-Kendall analysis [34, 35], our previous study indicated an abrupt decrease in the flood-season precipitation (June-September) around the year of 1979 [3]. The same statistical method was applied to NINO3.4 to detect its temporal trend and potential "breakpoint." In addition, nonparametric Kruskal-Wallis test was conducted to compare precipitation under moderateto-strong El Niño and La Niña years. The other approach was based on the spatial correlation between precipitation in the HRB and antecedent SST of the globe. By generating a global map of correlation coefficients, this method could identify oceanic areas with the most significant signal of teleconnection to the HRB. Similar to data analysis on SST, precipitation is to correlate with antecedent soil moisture in the HRB.

Mountain areas, with more than 1,000 reservoirs which contribute $97 \%$ of the total reservoir capacity of the basin, are important for both flood control and water supply in the study area. Therefore, probability analysis on the synchronous-asynchronous encounter was conducted for precipitation between north and south mountain regions. For a specific year, the region with above-normal precipitation could be a water supplier to the other region which coincidentally experiences a drought condition. This analysis was designed to generate information for the management and optimization of local water resources within the HRB, given the great uncertainty associated with climate change and water diversion project. Clayton copula was used in this study to estimate the joint probability distribution between the two regions of north and south mountains [36].

\subsection{Statistical Approaches}

2.4.1. Sequential Mann-Kendall Analysis. Temporal trend in the NINO3.4 was analyzed based on the rank-based nonparametric Mann-Kendall statistical test [34, 35]. The method has been commonly used for trend detection due to its robustness for nonnormally distributed data, which are frequently encountered in hydroclimatic time series [37, 38]. Although climate change is considered to occur in a transient manner, the magnitudes or relative contributions to the total detected changes in a period vary from year to year. Therefore, a "breakpoint" of the change may be statistically determined, and based on the "breakpoint" the entire study period could be segmented into subperiods for further investigations. This approach was widely used for studies on hydrologic and climatic studies in many regions [37, 39-42]. In this study, the sequential version of the Mann-Kendall test was conducted to analyze the abrupt change of the hydroclimatic time series $[34,35]$.

Given a data series composed of $x_{1}, x_{2}, \ldots, x_{n}$, for each element, the Mann-Kendall rank statistic $\left(d_{k}\right)$ is calculated as the summation of $m_{i}$, which is the number of later terms in the series whose values exceed $x_{i}$ :

$$
d_{k}=\sum_{i=1}^{k} m_{i} \quad(2 \leq k \leq n) .
$$

The mean and variance of the test statistic $d_{k}$ are

$$
\begin{gathered}
E\left[d_{k}\right]=\frac{k(k-1)}{4}, \\
\operatorname{var}\left[d_{k}\right]=\frac{k(k-1)(2 k+5)}{72} \quad(2 \leq k \leq n) .
\end{gathered}
$$

The sequential values of the statistic $u\left(d_{k}\right)$ are then calculated as

$$
u\left(d_{k}\right)=\frac{d_{k}-E\left[d_{k}\right]}{\sqrt{\operatorname{var}\left[d_{k}\right]}}
$$

The terms of the $u\left(d_{k}\right)(1 \leq k \leq n)$ constitute a forward sequence curve (C1). The same method is then applied to the inversed series and gets a backward sequence (C2). The intersection point of $\mathrm{C} 1$ and $\mathrm{C} 2$ located between the confidence interval is the time when a change point occurred.

2.4.2. Probability Analysis on Annual Precipitation. Monthly rainfall data in the study area was assumed to follow a LogPearson III distribution (PL3). The PL3 has been widely used in charactering hydrological variables including both precipitation and streamflow and generates better fits for annual precipitation in the HRB compared to other commonly used functions. The probability density function, $f(x)$, and 
cumulative distribution function, $F(x)$, of the distribution for the PL3 are expressed as follows [43]:

$$
\begin{gathered}
f(x)=\frac{1}{x|\beta| \Gamma(\alpha)}\left(\frac{\ln (x)-\gamma}{\beta}\right)^{\alpha-1} \exp \left(-\frac{\ln (x)-\gamma}{\beta}\right), \\
F(x)= \begin{cases}\frac{\Gamma(\alpha, \omega)}{\Gamma(\alpha)}, & \beta>0, \\
1-\frac{\Gamma(\alpha, \omega)}{\Gamma(\alpha)}, & \beta<0,\end{cases} \\
\omega=\frac{\ln (x)-\gamma}{\beta},
\end{gathered}
$$

where $x$ is the time series of monthly rainfall data at each station or is averaged at a given subregion. The distribution parameters $(\alpha, \beta$, and $\gamma)$ were calculated by the maximum likelihood estimation. $\Gamma(\alpha)$ and $\Gamma(\omega, \alpha)$ are gamma function and incomplete gamma function, respectively. Note that some statistical package, for example, MATLAB, considers the ratio of $\Gamma(\omega, \alpha) / \Gamma(\alpha)$ as incomplete gamma function.

2.4.3. Copula Analysis. Copula theory was applied in this study for determining the joint probability of annual precipitation in the north and south mountain areas of the HRB. A copula is a function that joins or couples multiple distribution functions to their one-dimensional marginal distribution functions [44]. For two dependent variables $x_{1}$ and $x_{2}$ with marginal distributions of $F\left(x_{1}\right)$ and $F\left(x_{2}\right)$, their joint distribution is

$$
C\left(x_{1}, x_{2}\right)=\operatorname{Pr}\left(X_{1} \leq x_{1}, X_{2} \leq x_{2}\right),
$$

where the function $C$ is a copula function representing the bivariate dependence structure of variables $X$ and $Y$. The copula representation is unique for (5), if the marginal distributions of $X$ and $Y$ are continuous [33]. Among the different types of copulas, Clayton copula [36] was used in this study with the following bivariate copula function:

$$
C\left(x_{1}, x_{2}\right)=\left[F\left(x_{1}\right)^{-\theta}+F\left(x_{2}\right)^{-\theta}-1\right]^{-1 / \theta} .
$$

For the Clayton copula [36], the generator $\varphi(u)=u-a-1$, and the corresponding bivariate copula function is defined as

$$
C_{\varphi}\left(u_{1}, u_{2}\right)=\left(u_{1}^{-\alpha}+u_{2}^{-\alpha}-1\right)^{-1 / \alpha}
$$

The Clayton copula parameter $\alpha$ is given based on Kendall's correlation coefficient $(\tau)$ of the bivariate data set:

$$
\alpha=\frac{2 \tau}{1-\tau} .
$$

\section{Results and Discussion}

3.1. SST-Precipitation Correlation. Average NINO3.4 during the summer flood season of the HRB (June to August) is negatively correlated with precipitation $(r=-0.316$,
$P=0.013)$ during the same season, also correlated to annual precipitation $(r=-0.326, P=0.010)$. Similar relationships were also observed between summer precipitation in the $\mathrm{HRB}$ and antecedent NINO3.4. Generally, higher NINO3.4 suggests lower summer and annual precipitation, and this is also confirmed by the fact that precipitation in years with moderate and high El Niño events was significantly lower than other years (445 versus $532 \mathrm{~mm}$ /year, Kruskal-Wallis test, $P=0.005$ ).

Results of the sequential Mann-Kendall analysis indicated that the significant change of NINO3.4 from June to August was started in early 1980s and confirmed in 1985. This is consistent with the abrupt change of precipitation detected during the 1980s in the study area [3]. Two years with extremely high NINO3.4 (1987 and 1997) were observed in the later period, although the medians of NINO3.4 were not significantly changed between the two periods (before and after 1986).

Summer (June to August) precipitation over the HRB was correlated with gridded SST to generate a map showing the precipitation-SST association at global scale (Figure 2). Critical values of correlation coefficients are determined to be 0.250 (for the significance level of $P=0.05$ ) and 0.33 $(P=0.01)$ with the given degree of freedom $(n-2$, where $n=60$ is the total number of years in this study period). In addition to the scattered areas around the global ocean, significant correlations were mainly observed in the eastern tropical Pacific Ocean and the western tropical Indian Ocean, suggesting the important roles of the two oceans in influencing summer precipitation in the HRB, especially for the south part of the basin. The spatial pattern of correlation coefficients suggested that the summer precipitation in the $\mathrm{HRB}$ was most likely associated with the Eastern-Pacific (EP) type El Niño for which the El Niño SST anomalies are located near the South American coast. Therefore, a representative area was identified as the area with strong teleconnection for precipitation in the HRB. Area 1 is located in the ENSO center of action and with a coverage comparable to the east portion of the El Niño region $3\left(90^{\circ}-150^{\circ} \mathrm{W}\right.$ and $\left.5^{\circ} \mathrm{N}-5^{\circ} \mathrm{S}\right)$. Similarly, SST area 2 was identified between $45^{\circ}-60^{\circ} \mathrm{E}$ and $5^{\circ} \mathrm{N}-5^{\circ} \mathrm{S}$, generally enclosed by the region of Western Tropical Indian Ocean SST index (WTIO, $50^{\circ}-70^{\circ} \mathrm{E}$ and $10^{\circ} \mathrm{N}-10^{\circ} \mathrm{S}$ ).

The capability of SST in the identified areas on predicting summer precipitation in the HRB was evaluated with the leave-one-out cross-validation approach. For a specific year in the 60-year period, precipitation was predicted based on the linear regression function derived using the other 59year data of observed precipitation and spatial average SSTs in the two areas (Figure 3). SSTs in areas 1 and 2 generated significant prediction on summer precipitation of the HRB at $95 \%$ confidence interval and explained $25 \%$ of the total variance in precipitation. Further investigation indicated that better model performance $\left(R^{2}=0.90\right)$ was observed for years with EP type El Niño events identified by Yu et al. [45].

3.2. Soil Moisture. Annual average soil moisture over the HRB ranged from 0.16 to 0.21 during 1979-2010. Temporally, a significant decreasing trend was detected for annual 


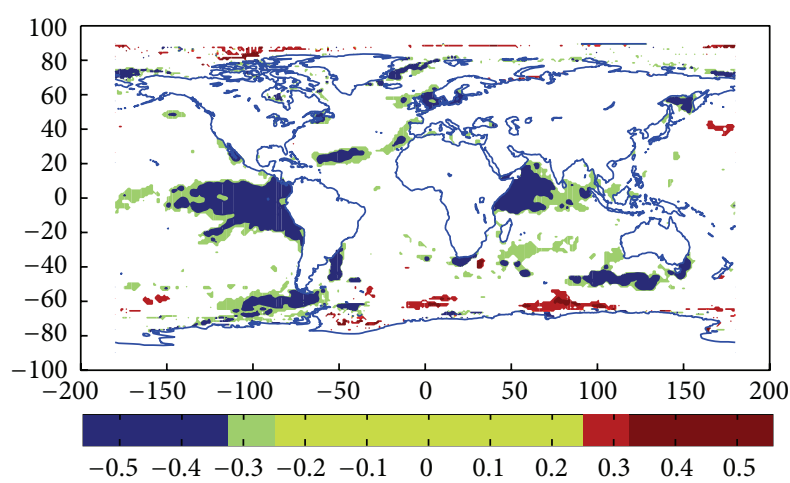

Figure 2: The correlation between summer (June to August) precipitation in the Haihe River Basin and global SST of the same months during 1951-2010. Correlation coefficients larger than the critical values of $\pm 0.25(P<0.05)$ and $\pm 0.33(P<0.01)$ are highlighted.

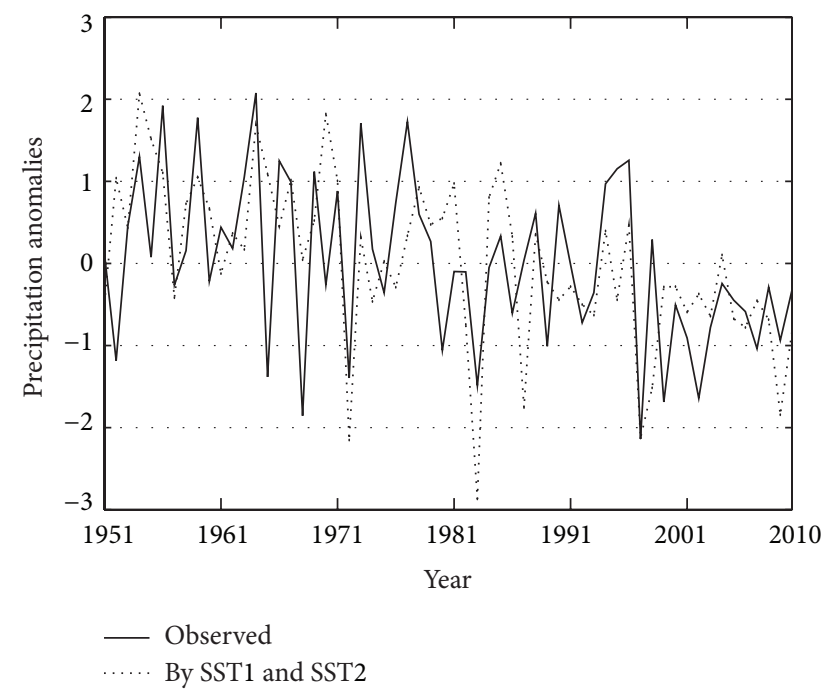

FIgURE 3: Observed and predicted summer precipitation in the HRB during 1951-2010 $\left(R^{2}=0.25\right.$, based on the leave-one-out crossvalidation approach).

averages of soil moisture according to the Mann-Kendall test $(P=0.002)$. As annual averages, soil moisture was not related to precipitation. However, monthly data of soil moisture and precipitation showed significant associations $(r=0.49, P<$ $0.001)$. Highest correlation coefficient was observed with a lag of $-1(r=0.57)$, suggesting about one-month delay of soil moisture in response to the change on precipitation. This relationship also explained the seasonality of soil moisture: highest values were observed during summer months of July to September with long-term average of 0.21 , while for other months the values were relatively lower (0.17). Antecedent soil moisture had negligible effects on monthly precipitation according to the results of cross correlation analysis between the two time series. The months immediately before rainfall season, that is, April to June, were associated with low-thanaverage soil moistures.

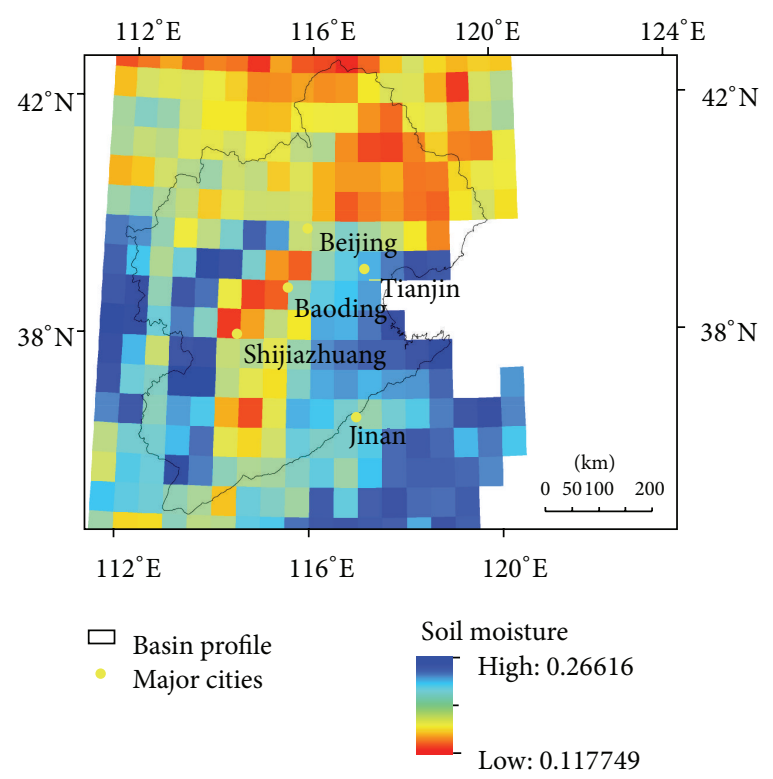

FIgURE 4: Soil moisture $\left(0.25^{\circ} \times 0.25^{\circ}\right)$ in the Haihe River Basin, presented as averages during 1979-2010.

Spatially, relatively wet soils were observed in the coastal area and over the Taihangshan Mountains (Figure 4). The Yanshan Mountains (north to Beijing) and metropolitan areas of Beijing, Tianjin, Baoding, and Shijiazhuang were associated with lower soil moistures. For annual precipitation of the HRB, there was a general decreasing trend in precipitation from east to west or from the coastline to the mountainous area [3]. Therefore, no spatial correlation was confirmed between soil moisture and precipitation as basinwide averages.

3.3. Synchronous-Asynchronous Encounter Probability Analysis. Copula analysis was conducted for the precipitations between subregions of north and south mountain areas. In this study, we defined a "wet year" or a "dry year" based on the cumulative distribution of precipitation summarized for the corresponding subregion. Specifically, a dry year was associated with annual precipitation $<37.5$ th percentile of the precipitations in the study period, while a wet year was with annual precipitation $>62.5$ th percentile (Figure 5 ). This definition was consistent with that suggested in the Handbook for Surface-Water Resources Investigations published by the Chinese Ministry of Water Resources. In addition, similar classification was used in the previous studies in analyzing precipitation in the same study area $[12,46]$.

Critical values (presented as dashed line in Figure 6) of dry and wet years in each region divided the joint probability into sections. For example, the section for simultaneous dry years for both north and south regions was related to a joint probability of about $20 \%$, suggesting that, in about $20 \%$ of all years, north and south mountains of the HRB would experience dry conditions in terms of annual precipitation. It was consistent with the observed data, in which simultaneous dry years were detected in 12 years during the 60 -year period 


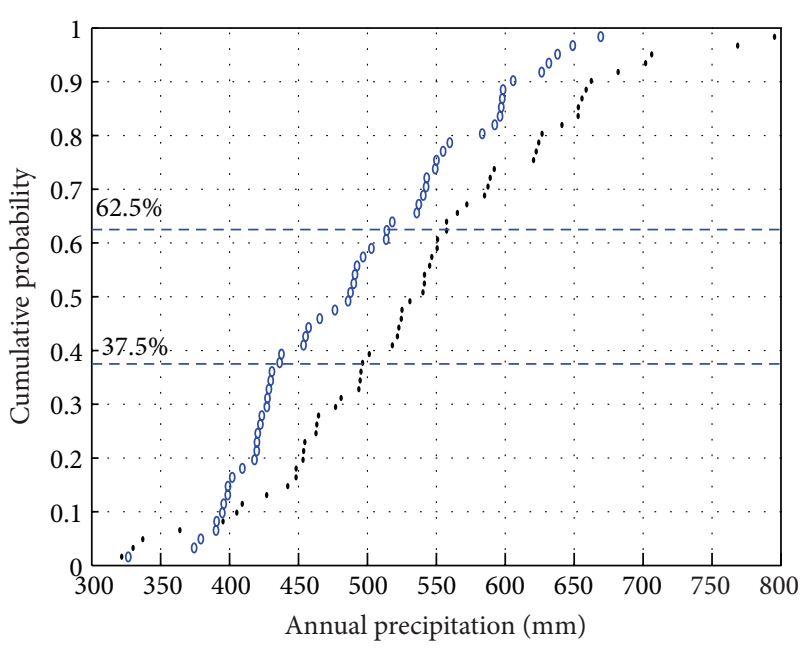

- North mountains

South mountains

FIGURE 5: Cumulative distribution of annual precipitation in the north and south mountainous regions of the Haihe River Basin.

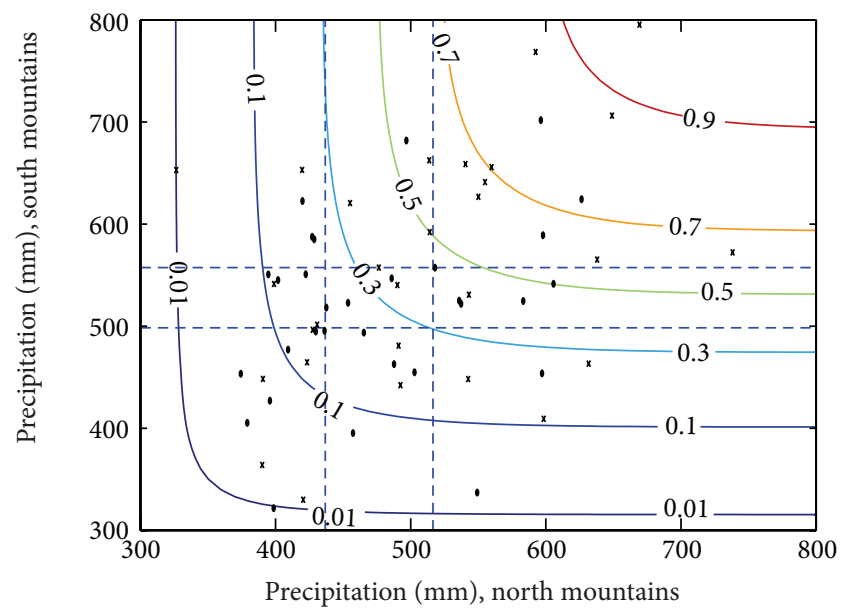

FIGURE 6: Isolines of the joint probability distribution by the Clayton copula for the annual precipitation in the north and south mountainous regions of the Haihe River Basin. Crosses and dots are measured precipitation in north and south region, respectively. Dashed lines indicate the critical values for dry year $(<37.5 \%)$ and wet year ( $>62.5 \%$ of the cumulative precipitation) for each region.

of 1951-2010, with 5 years in Period I (before 1980) and 7 years in Period II (after 1980). Simultaneous dry conditions within the HRB were more frequently observed in Period II, suggesting an increasing demand of water supply from outside of the basin.

Copula results of joint probability of precipitation between north and south mountain areas provided information for potential cross-watershed water diversion within the HRB. Within the HRB, water management and flood utilization should focus on the situation where one region is in wet years, while the other is in either a dry or a normal year. In this case, the former region could be considered as a
TABLE 1: Probabilities of synchronous-asynchronous encounter of precipitation in the Haihe River Basin.

\begin{tabular}{lccc}
\hline & $\begin{array}{c}\text { Wet in the north } \\
\text { and normal/dry } \\
\text { in the south }\end{array}$ & $\begin{array}{c}\text { Wet in the south } \\
\text { and normal/dry } \\
\text { in the north }\end{array}$ & Total \\
\hline Theoretical probability & $14.8 \%$ & $24.3 \%$ & $39.1 \%$ \\
Years in Period I & 4 & 6 & 10 \\
Years in Period II & 6 & 3 & 9 \\
\hline
\end{tabular}

potential water resource for the latter one. Copula analysis suggested a theoretical probability of $39.1 \%$ from crosswatershed water diversion, including $14.8 \%$ for diversion from the north to south and $24.3 \%$ from the south to north (Table 1). With measured precipitation, 19 years during the 60-year period of 1951-2010 were identified with the potential for cross-watershed management, with 10 years in Period I (1951-1980) and 9 in Period II (1981-2010). In Period II, there were 6 years with the south mountains as a source of water supply to the north HRB, while there were only 3 years for the north mountain areas. This was consistent with the temporal trend of precipitation in the study area: although the south mountains were associated with higher annual precipitation $(541 \mathrm{~mm})$ than its north counterpart $(495 \mathrm{~mm})$ during the study period, it is also showed a higher rate of decrease (10\%) than that for the north mountains $(5.7 \%)$ between the two periods before and after 1980 .

\section{Conclusions}

The economic development in the Haihe River Basin has been increasingly constrained by water scarcity, especially for agricultural water demands. The region produces about $30 \%$ of wheat and $20 \%$ of corn of China and requires a significant amount of irrigation water during winters and early springs. Extreme weather conditions have imposed substantial effects on the food security in HRB. For example, the 2010-11 drought in North China, which was the worst drought to hit the country in 60 years, affected most of wheatproducing regions in HRB. Given limited water resources in the study area, water management is required to improve the efficiency in stormwater utilization, storage, and allocation.

This study investigated the spatiotemporal variability on the precipitation in the Haihe River Basin during 1951-2010. During the summer flood season in the study area, basinwide precipitation was negatively correlated with average NINO3.4. Generally, higher NINO3.4 suggests lower summer and annual precipitation. Spatially, summer precipitation was correlated with gridded SST observed in the eastern tropic Pacific Ocean and the western tropic Indian Ocean. SST in two representative areas was identified as potential predictors for precipitation in the HRB. No spatial or temporal correlations were confirmed between precipitation and soil moisture as annual averages in the study area. Copula analysis of joint probability of precipitation between north and south mountain areas provided information for potential cross-watershed water diversion within the HRB. The results 
suggested about $40 \%$ possibility in a year with a potential for cross-watershed water diversion within HRB.

\section{Conflict of Interests}

The authors declare that there is no conflict of interests regarding the publication of this paper.

\section{Acknowledgments}

This study is supported by the Open Research Fund of Key Laboratory of Water Cycle and Related Land Surface Processes, Institute of Geographical Science and Natural Resources Research, Chinese Academy of Science, Grant no. 2011A001. The authors would like to acknowledge funding support from the Key Project for the Natural Sciences Foundation of China (41271048). CPC Soil Moisture data are provided by the NOAA/OAR/ESRL PSD, Boulder, CO, USA (http://www.esrl.noaa.gov/psd/).

\section{References}

[1] J. Xia, H. Feng, C. Zhan, and G. Niu, "Determination of a reasonable percentage for ecological water-use in the Haihe River Basin, China," Pedosphere, vol. 16, no. 1, pp. 33-42, 2006.

[2] J. L. Domagalski, X. Zhou, C. Lin et al., Comparative WaterQuality Assessment of the Hai He River Basin in the People's Republic of China and Three Similar Basins in the United States, U.S. Geological Survey Professional Paper 1647, U.S. Department of the Interior, U.S. Geological Survey, Reston, Va, USA, 2010.

[3] Z. Wang, Y. Luo, C. Liu, J. Xia, and M. Zhang, "Spatial and temporal variations of precipitation in Haihe River Basin, China: six decades of measurements," Hydrological Processes, vol. 25, no. 18, pp. 2916-2923, 2011.

[4] Y. Ding, G. Ren, G. Shi et al., "China's national assessment report on climate change (I): climate change in China and the future trend," Advances in Climate Change Research, vol. 3, pp. 1-5, 2007.

[5] F. Guo and G. Liu, "Preliminary analysis of the utilization of storms in Haihe River Basin," Haihe Water Resources, vol. 2004, pp. 8-11, 2004 (Chinese).

[6] S. Zeng, L. Zhang, and J. Xia, "Impacts of climate change on the hydrological cycle in the Haihe basin," in Proceedings of the International Symposium on Water Resource and Environmental Protection (ISWREP '11), pp. 1107-1110, Xi'an, China, May 2011.

[7] J. T. Chu, J. Xia, C.-Y. Xu, and V. P. Singh, "Statistical downscaling of daily mean temperature, pan evaporation and precipitation for climate change scenarios in Haihe River, China," Theoretical and Applied Climatology, vol. 99, no. 1-2, pp. 149-161, 2010.

[8] Q. Li and Y. Ding, "Climate simulation and future projection of precipitation and the water vapor budget in the Haihe River basin," Acta Meteorologica Sinica, vol. 26, no. 3, pp. 345-361, 2012.

[9] S. Piao, P. Ciais, Y. Huang et al., "The impacts of climate change on water resources and agriculture in China," Nature, vol. 467, no. 7311, pp. 43-51, 2010.

[10] Q. Zhang, Z. Xu, Z. Shen, S. Li, and S. Wang, "The Han River watershed management initiative for the South-to-North Water
Transfer Project (Middle Route) of China," Environmental Monitoring and Assessment, vol. 148, no. 1-4, pp. 369-377, 2009.

[11] X. Liu, C. Liu, Y. Luo, M. Zhang, and J. Xia, "Dramatic decrease in streamflow from the headwater source in the central route of China's water diversion project: climatic variation or human influence?" Journal of Geophysical Research D, vol. 117, no. 6, Article ID D06113, 2012.

[12] X. Liu, C. Liu, Y. Luo, and M. Zhang, "Increasing probability of a simultaneous dry year between the water source and destination of the central route of China's water diversion project," Geophysical Research Letters, 2013.

[13] R. Mei and G. Wang, "Impact of sea surface temperature and soil moisture on summer precipitation in the united states based on observational data," Journal of Hydrometeorology, vol. 12, no. 5, pp. 1086-1099, 2011.

[14] A. Capotondi and M. A. Alexander, "Relationship between precipitation in the great plains of the United States and global SSTs: insights from the IPCC AR4 models," Journal of Climate, vol. 23, no. 11, pp. 2941-2958, 2010.

[15] J.-Y. Yu and Y. Zou, "The enhanced drying effect of CentralPacific El Niño on US winter," Environmental Research Letters, vol. 8, Article ID 014019, 2013.

[16] C. M. Mills and J. E. Walsh, "Seasonal variation and spatial patterns of the atmospheric component of the pacific decadal oscillation," Journal of Climate, vol. 26, no. 5, pp. 1575-1594, 2013.

[17] L. Li, W. Li, and A. P. Barros, "Atmospheric moisture budget and its regulation of the summer precipitation variability over the Southeastern United States," Climate Dynamics, vol. 41, no. 3-4, pp. 613-631, 2013.

[18] R. W. Higgins and V. E. Kousky, "Changes in observed daily precipitation over the United States between 1950-79 and 19802009," Journal of Hydrometeorology, vol. 14, no. 1, pp. 105-121, 2013.

[19] R. Wu, S. Yang, Z. Wen, G. Huang, and K. Hu, "Interdecadal change in the relationship of southern China summer rainfall with tropical Indo-Pacific SST," Theoretical and Applied Climatology, vol. 108, no. 1-2, pp. 119-133, 2012.

[20] Y. Cheng, U. Lohmann, J. Zhang, Y. Luo, Z. Liu, and G. Lesins, "Contribution of changes in sea surface temperature and aerosol loading to the decreasing precipitation trend in southern China," Journal of Climate, vol. 18, no. 9, pp. 1381-1390, 2005.

[21] L. Zhou, C. Tam, W. Zhou, and J. C. L. Chan, "Influence of South China Sea SST and the ENSO on winter rainfall over South China," Advances in Atmospheric Sciences, vol. 27, no. 4, pp. 832844, 2010.

[22] E. A. B. Eltahir, "A soil moisture-rainfall feedback mechanism: 1. Theory and observations," Water Resources Research, vol. 34, no. 4, pp. 765-776, 1998.

[23] K. L. Findell and E. A. B. Eltahir, "Atmospheric controls on soil moisture-boundary layer interactions-part I: framework development," Journal of Hydrometeorology, vol. 4, pp. 552-569, 2003.

[24] K. L. Findell and E. A. B. Eltahir, "Atmospheric controls on soil moisture-boundary layer interactions. Part II: feedbacks within the continental United States," Journal of Hydrometeorology, vol. 4, pp. 570-583, 2003.

[25] R. L. Edmonds, "Geography and natural resources," in Beijing and Tianjin, towards a Millennial Megalopolis, B. Hook, Ed., vol. 4, pp. 56-103, Oxford University Press, Oxford, UK, 1998. 
[26] CMA Surface Meteorologic Data of China, China Meteorologic Data Sharing Service System, China Meteorological Administration, Beijing, China, http://cdc.cma.gov.cn.

[27] N. A. Rayner, D. E. Parker, E. B. Horton et al., "Global analyses of sea surface temperature, sea ice, and night marine air temperature since the late nineteenth century," Journal of Geophysical Research D: Atmospheres, vol. 108, no. 14, Article ID ACL2-1-22, 2003.

[28] C. Li and J. Pan, "Atmospheric circulation characteristics associated with the onset of Asian summer monsoon," Advances in Atmospheric Sciences, vol. 23, no. 6, pp. 925-939, 2006.

[29] K. E. Trenberth, “The Definition of El Niño," Bulletin of the American Meteorological Society, vol. 78, no. 12, pp. 2771-2777, 1997.

[30] ESA Global ECV soil moisture data, The European Space Agency (ESA)'s climate change initiative (CCI), 2013, http: //www.esa-soilmoisture-cci.org/.

[31] H. van den Dool, J. Huang, and Y. Fan, "Performance and analysis of the constructed analogue method applied to U.S. soil moisture over 1981-2001," Journal of Geophysical Research D: Atmospheres, vol. 108, no. 16, pp. 1-16, 2003.

[32] Y. Fan and H. van den Dool, "Climate Prediction Center global monthly soil moisture data set at $0.5^{\circ}$ resolution for 1948 to present," Journal of Geophysical Research D: Atmospheres, vol. 109, no. D10, 2004.

[33] Z. Wang, Y. Luo, X. Zhu, R. Wang, W. Li, and M. Zhang, "Watershed modeling of surface water-groundwater interaction under projected climate change and water management in the Haihe River basin, China," British Journal of Environment and Climate Change, vol. 3, no. 3, pp. 421-443, 2013, A Special Issue in Honor of Distinguished Professor Miguel A. Mariño: Modeling Approaches to Study Climate Change Impacts on Water and Environmental Systems.

[34] H. B. Mann, "Nonparametric tests against trend," Econometrica, vol. 13, pp. 245-259, 1945.

[35] M. G. Kendall, Rank Correlation Measures, Charles Griffin, London, UK, 1975.

[36] D. G. Clayton, "A model for association in bivariate life tables and its application in epidemiological studies of familial tendency in chronic disease incidence," Biometrika, vol. 65, no. 1, pp. 141-151, 1978.

[37] H. Zheng, L. Zhang, R. Zhu, C. Liu, Y. Sato, and Y. Fukushima, "Responses of streamflow to climate and land surface change in the headwaters of the Yellow River Basin," Water Resources Research, vol. 45, no. 7, Article ID W00A19, 2009.

[38] S. Yue and C. Y. Wang, "Applicability of prewhitening to eliminate the influence of serial correlation on the MannKendall test," Water Resources Research, vol. 38, no. 6, pp. 41-47, 2002.

[39] G. Wang, J. Xia, and J. Che, "Quantification of effects of climate variations and human activities on runoff by a monthly water balance model: a case study of the Chaobai River basin in northern China," Water Resources Research, vol. 45, no. 7, Article ID W00A11, 2009.

[40] D. Wang and M. Hejazi, "Quantifying the relative contribution of the climate and direct human impacts on mean annual streamflow in the contiguous United States," Water Resources Research, vol. 47, no. 9, Article ID W00J12, 2011.

[41] T. Partal and E. Kahya, "Trend analysis in Turkish precipitation data," Hydrological Processes, vol. 20, no. 9, pp. 2011-2026, 2006.
[42] M. M. Samdi and A. Zghoul, "A sudden change in rainfall characteristics in Amman, Jordan during the mid," The American Journal of Environmental Sciences, vol. 2, pp. 84-91, 2006.

[43] K. Hoshi and S. J. Burges, "Sampling properties of parameter estimates for the log Pearson type 3 distribution, using moments in real space," Journal of Hydrology, vol. 53, no. 3-4, pp. 305-316, 1981.

[44] R. B. Nelsen, An Introduction to Copulas, Springer Series in Statistics, Springer, New York, NY, USA, 2006.

[45] J.-Y. Yu, Y. Zou, S. T. Kim, and T. Lee, "The changing impact of El Niño on US winter temperatures," Geophysical Research Letters, vol. 39, no. 15, Article ID L15702, 2012.

[46] Q. Xiong, X. He, and L. Kang, " Synchronous asynchronous encounter probability of rich poor precipitation between water source area and water receiving area based on copula theory in middle route of south to north water transfer project," Water Resources and Power, vol. 27, pp. 9-11, 2009. 

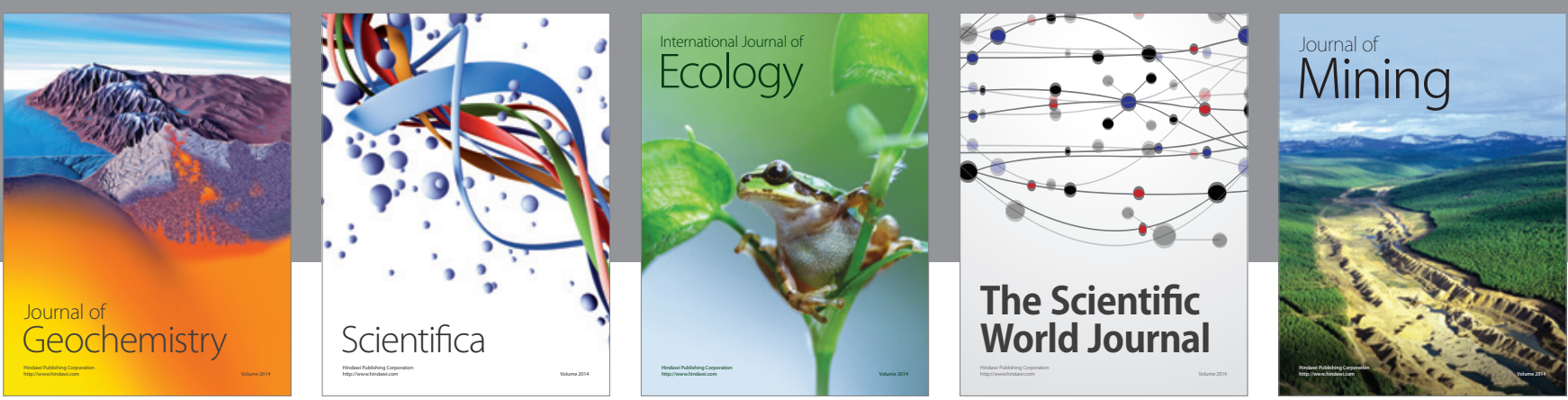

The Scientific World Journal
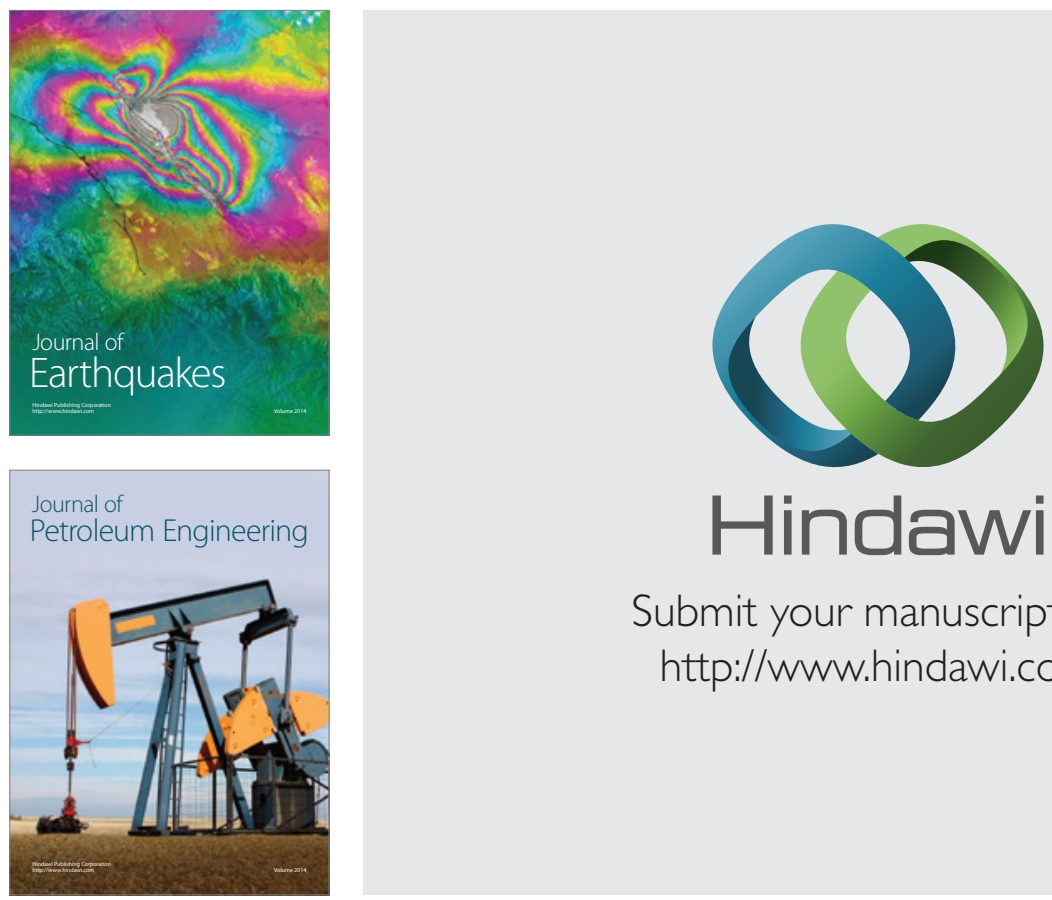

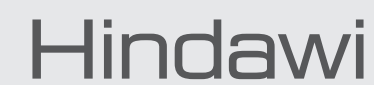

Submit your manuscripts at

http://www.hindawi.com
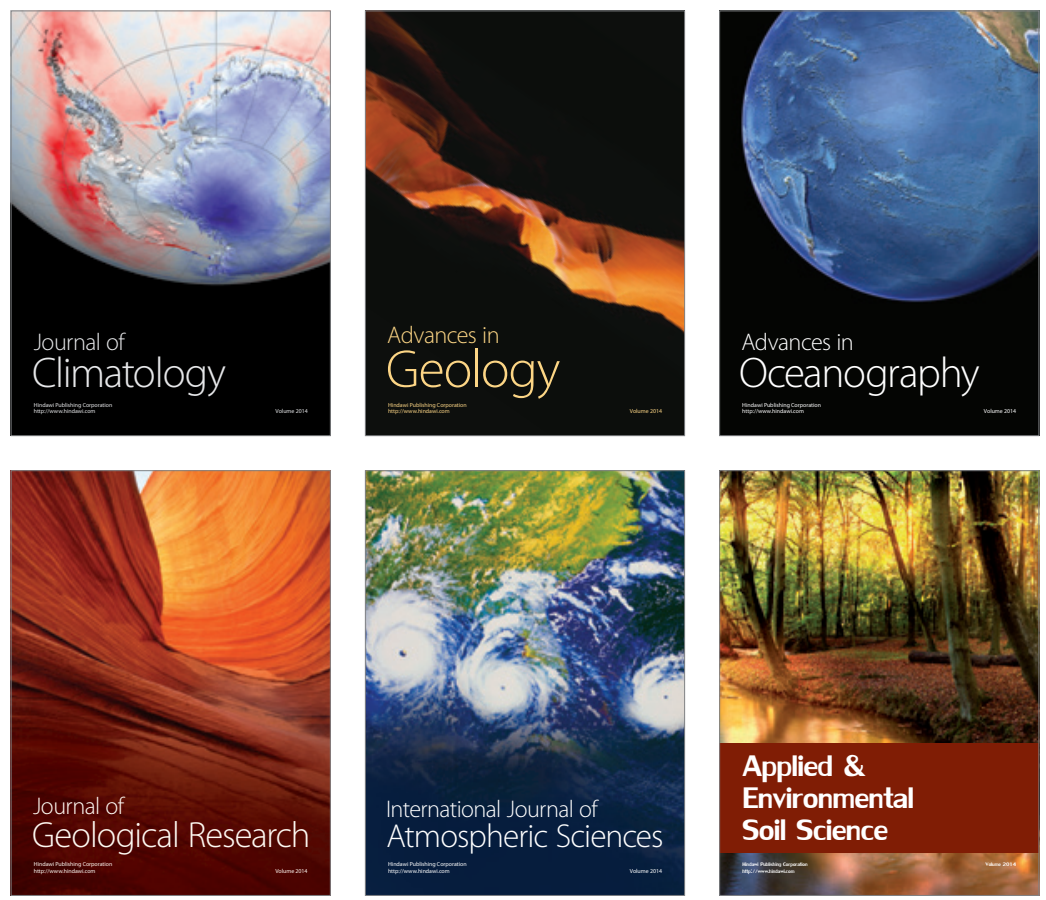
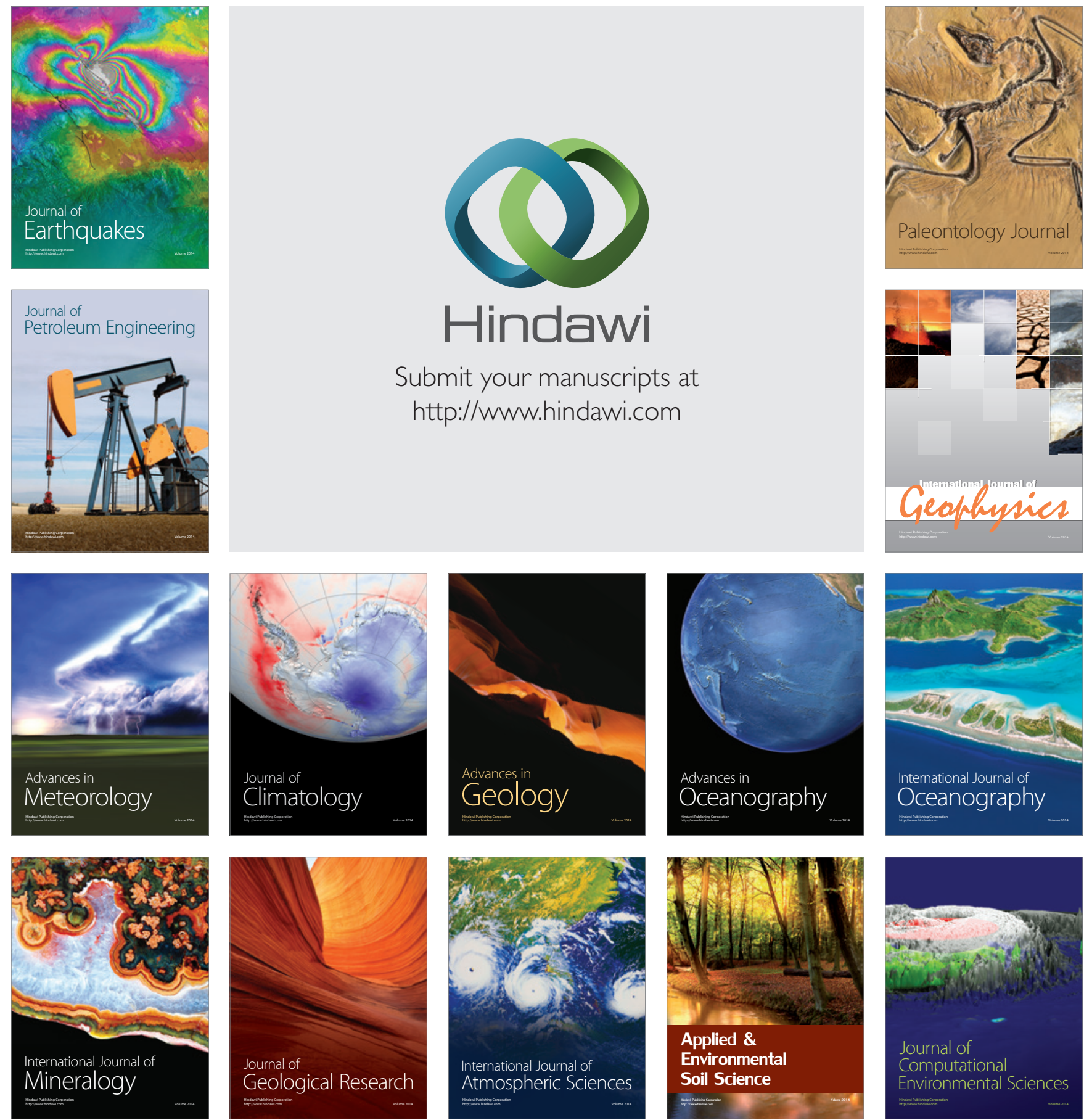